\title{
ARTICLES
}

\section{Simultaneous Quantitation of Topoisomerase II $\alpha$ and $\beta$ Isoform mRNAs in Lung Tumor Cells and Normal and Malignant Lung Tissue}

\author{
Shelagh E. L. Mirski, Theodora Voskoglou-Nomikos, Leah C. Young, \\ Roger G. Deeley, Barbara G. Campling, James H. Gerlach, and Susan P. C. Cole \\ Cancer Research Laboratories, Queen's University, Kingston, Ontario, Canada
}

SUMMARY: Certain drugs used in the treatment of lung cancer and other human malignancies are cytotoxic because of their ability to interact with the two isoforms of topoisomerase II (topo II), topo II $\alpha$ and topo II $\beta$. As part of an effort to evaluate the contribution of topo II alterations to drug sensitivity and resistance in lung cancer, we have developed a semi-quantitative reverse transcriptase-polymerase chain reaction (RT-PCR) assay to measure levels of topo II $\alpha$ and $\beta$ mRNAs simultaneously using a single pair of primers with sequences common to both isoforms. The PCR products derived from the topo II $\alpha$ and $\beta$ mRNAs are both $446 \mathrm{bp}$ but have different electrophoretic mobilities in a nondenaturing polyacrylamide gel, allowing sensitive, rapid quantitation when the products are radiolabeled with $\left[{ }^{35} \mathrm{~S}\right]-\mathrm{dATP}$. Using this RT-PCR method, poly $(\mathrm{A}+)$ RNA from 13 non-small cell lung cancer (NSCLC) cell lines was analyzed. The results obtained indicated that the cell lines express a wide range of topo $\| \alpha$ mRNA levels (12-fold) and topo $\| \beta$ mRNA levels (5.5-fold). Tumor and normal lung tissues from 25 patients with NSCLC were also examined. In the tumor samples, the levels of the topo II $\alpha$ and $\beta$ mRNAs were similar. However, mean topo Il $\alpha$ mRNA levels in the tumors were approximately 7 -fold higher than those of the paired normal lung tissues. In contrast, topo $\| \beta$ mRNA levels were similar in both tumor and normal lung. Topo II $\alpha$ and $\beta$ mRNA levels were both significantly lower in the squamous cell tumors than in the adenocarcinoma samples. Topo II $\beta$ mRNA levels in the squamous cell tumors were also significantly lower than those in paired normal lung tissue. The RT-PCR method described is reliable and convenient, and for the first time, makes the rapid simultaneous direct comparison of topo Il $\alpha$ and topo $\| \beta$ mRNA levels feasible in large numbers of clinical samples. (Lab Invest 2000, 80:787-795).

$T$ opoisomerase II (topo II) is a nuclear enzyme that alters the topology of DNA and is essential for normal chromosome segregation at mitosis. In mammalian cells, there are two isoforms, designated topo $\| \alpha$ and topo $\| \beta$, which share more than $70 \%$ amino acid identity, but differ in their relative levels of expression in developing embryonic tissues, normal adult tissues, and tumors (Mirski and Cole, 1997). A number of clinically important anticancer drugs interact with topo II to produce DNA damage and cell death by apoptosis. Topo II poisons, such as VP-16 (etoposide) and doxorubicin, stabilize an intermediate of the enzyme's catalytic cycle, the "cleaved complex" of topo II, DNA, and drug. Resistance to these topo II targeting drugs arises through a number of different mechanisms in human tumor cell lines, including decreased

Received October 28, 1999.

This work was supported by a grant from the National Cancer Institute of Canada with funds from the Terry Fox Run.

Address reprint requests to: Dr. S.P.C. Cole, Cancer Research Laboratories, Rm 328 Botterell Hall, Queen's University, Kingston, Ontario, Canada K7L 3N6. Fax: 613-533-6830; E-mail: coles@post.queensu.ca levels of the enzyme, mutations in the ATPase or DNA breakage and religation domains, or, in the case of the $\alpha$ isoform, decreased nuclear localization (Larsen and Skladanowski, 1998; Mirski and Cole, 1997; Nitiss and Beck, 1996). A second class of topo II interactive drugs, which includes the investigational agents ICRF187 and ICRF-159, acts by directly inhibiting the enzyme. Sensitivity to these drugs is greater when topo Il $\alpha$ expression is diminished (Davies et al, 1997; Fattman et al, 1996), and resistance can result from mutations that do not confer resistance to topo II poisons (Sehested et al, 1998; Wessel et al, 1999). The $\alpha$ isoform of topo II is generally considered to be the more important target for cytotoxic therapy, and this isoform has been studied more extensively than topo II $\beta$. However, not yet fully defined are the relative contributions of the two isoforms to the sensitivity of tumor cells to the various agents that act either as topo II poisons or as catalytic inhibitors. There is some evidence that topo $\| \alpha$ and topo $\| \beta$ differ in their relative sensitivity to certain drugs (Cornarotti et al, 1996; Meczes et al, 1997; Perrin et al, 1998). Consequently, the selection of appropriate combinations of drugs that interact preferentially with the relevant 
isoform may offer advantages in overcoming clinical resistance (Dingemans et al, 1998).

In lung cancer the problem of drug resistance generally segregates with the two major forms of the disease. In small cell lung cancer (SCLC), resistance almost always develops after an initial response to chemotherapy, which frequently includes at least one topo II poison. In contrast, non-small cell lung cancer (NSCLC) is usually inherently resistant to such chemotherapy. Several groups have reported that levels of topo Il $\alpha$ protein and/or mRNA correlate with drug sensitivity in lung cancer cell lines and are often higher in SCLC than in NSCLC cell lines, as is consistent with the relative drug sensitivities of the two tumor types (Campling et al, 1997a; Giaccone et al, 1992; Kasahara et al, 1992). There are few studies with patient samples, but they also indicate that levels of topo $\| \alpha$ mRNA or protein are higher in SCLC than in NSCLC tumors (Dingemans et al, 1998; Guinee et al, 1996; Kreisholt et al, 1998; Syahruddin et al, 1998).

In the present study, using a single pair of genespecific primers, we have developed a convenient reverse transcriptase-polymerase chain reaction (RTPCR) method for the simultaneous quantitation of the relative levels of topo $\| \alpha$ and topo $\| \beta$ mRNAs in both NSCLC cell lines and patient samples. Analysis of 13 NSCLC cell lines, and tumor and normal lung tissues from 25 patients with NSCLC, revealed a wide range in expression levels of both topo II isoforms. Significant differences were observed between the tumor samples and paired normal lung tissues and, unexpectedly, between the adenocarcinoma and squamous cell carcinoma samples. The method described provides for the efficient use of the limited supply of RNA from clinical samples and permits, for the first time, the direct comparison of topo $\| \alpha$ and topo $\| \beta$ mRNA levels in an individual patient sample.

\section{Results}

\section{Polymerase Chain Reaction Primers for Simultaneous Amplification of Topo II $\alpha$ and Topo II $\beta$ cDNA}

To maximize the likelihood of obtaining specific PCR products, PCR primers suitable for simultaneous amplification of both topo II isoforms with equal efficiency were selected by identifying sequences in the mRNAs that were identical for 20 or more consecutive nucleotides and had a GC content between $40 \%$ and $60 \%$. Only two sequences met these criteria for the sense and antisense PCR primers (Fig. 1A). These primers amplify a 446 bp region of the topo II $\alpha$ and $\beta$ mRNAs that is $78 \%$ identical and encodes part of their respective DNA breakage/reunion domains. The region spans introns 12 to 15 of both genes (Fig. 1A) (Lang et al, 1998) so that PCR products of any genomic DNA that might contaminate the RNA preparations would be readily detectable (approximately $1.3 \mathrm{~kb}$ for TOP $2 A$ and $2.8 \mathrm{~kb}$ for TOP2B) and would not interfere with quantitation. Another important characteristic of this region is that the two topo II cDNA sequences contain different restriction sites, which would allow the topo
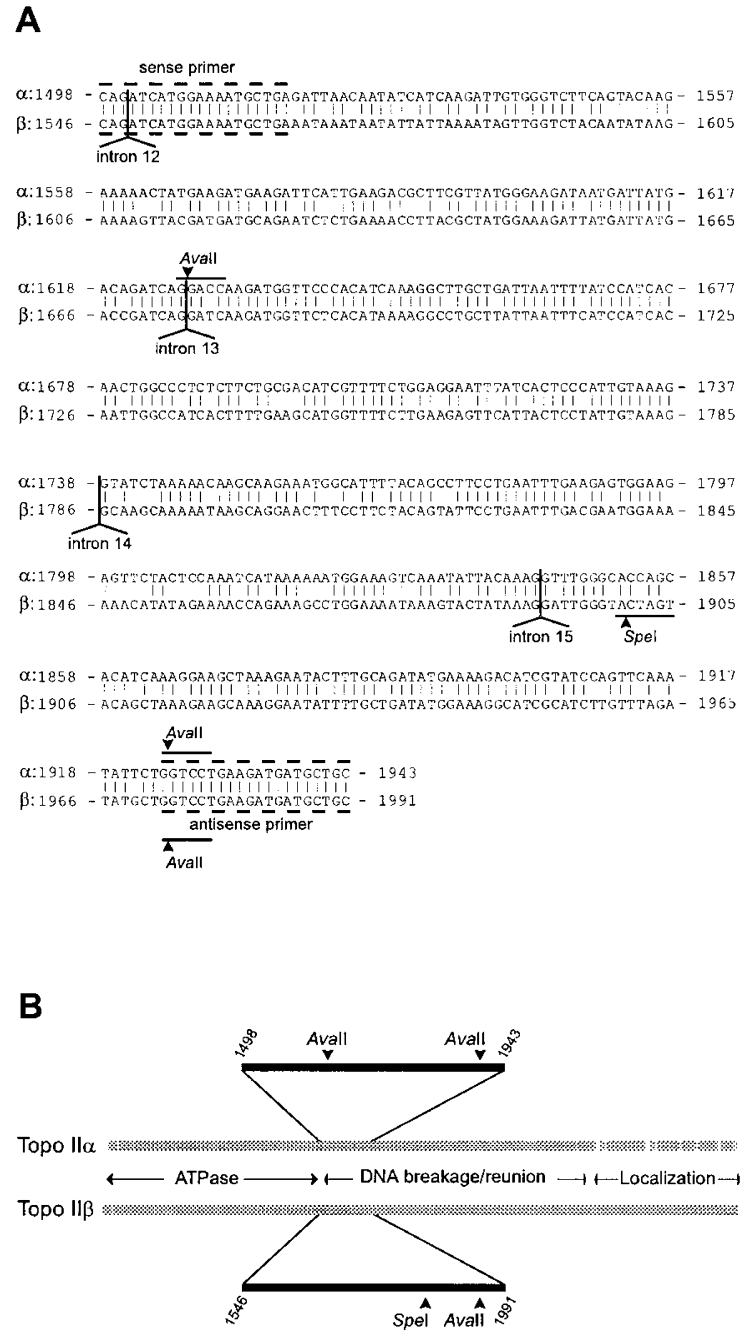

Figure 1.

$A$, Alignment of the nucleotide sequences of the regions of human topo $\mathrm{Il} \alpha$ and topo $\| \beta$ mRNAs amplified by RT-PCR. The alignment of the nucleotide sequences was based on CLUSTAL $W$ alignment of the amino acid sequences, and nucleotide sequence numbering is as described previously (Lang et al, 1998). Both topo II $\alpha$ and $\beta$ PCR products are 446 bp and share an overall sequence identity of $78 \%$. The positions of the sense and antisense primers used for the PCR amplification and the locations of the Avall and Spel restriction sites used for subsequent diagnostic restriction enzyme digestion are shown. Positions of intron-exon boundaries are also indicated (Lang et al, 1998). $B$, Schematic alignment of the amino acid sequences and domain organization of topo $\|_{\alpha} \alpha$ and topo $\| \beta$ (grey stippled bars) with the position of their respective 446 bp PCR products shown above and below (solid bars). Gaps in the grey stippled bars correspond to gaps introduced by CLUSTAL W to achieve optimal alignment of the amino acid sequences (Lang et al, 1998). The region of each cDNA corresponding to the 446 bp PCR product amplified by the sense and antisense primers shown in $A$, as well as the positions of the restriction sites used for subsequent diagnostic restriction enzyme digests, are indicated.

$\| \alpha$ and topo $\| \beta$ PCR products to be readily distinguished from each other. Thus, the $\alpha$ sequence contains two Avall sites, whereas the $\beta$ sequence contains one Avall site and one Spel site (Fig. 1).

The mixture of topo $\| \alpha / \beta$ PCR products comigrated as a single band on an agarose gel at the expected size of $446 \mathrm{bp}$ (Fig. 2A). In contrast, these products resolved as two distinct bands on a $5 \%$ nondenaturing polyacrylamide gel (Fig. 2B). To deter- 


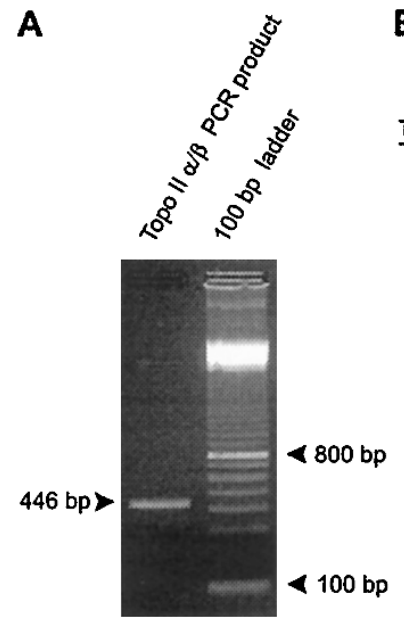

B

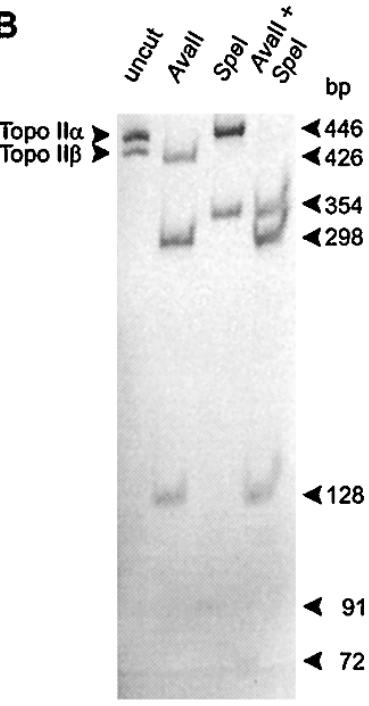

C

\begin{tabular}{|lccc|}
\hline \multicolumn{4}{|c|}{ Restriction Fragment Sizes (bp) } \\
\hline & Avall & Spel & Avall + Spel \\
\hline Topo Ila: & $128,298,19$ & 446 & $128,298,19$ \\
Topo IIB: & 426,19 & 354,91 & $354,72,19$ \\
\hline
\end{tabular}

\section{Figure 2.}

Analysis of topo Il $\alpha$ and topo II $\beta$ RT-PCR products from the H209 SCLC cell line by gel electrophoresis. $A$, The mixture of topo $\| \alpha$ and topo $\| \beta$ PCR products obtained using $\mathrm{H} 209$ cDNA as template and the single pair of gene-specific primers described in Figure 1 was resolved by agarose gel electrophoresis and stained with ethidium bromide. $B$, Image of $\left[{ }^{35} \mathrm{~S}\right] \mathrm{dATP}$ labeled topo II $\alpha$ and topo II $\beta$ PCR products and resolved by electrophoresis in a 5\% nondenaturing polyacrylamide gel. [ ${ }^{35} \mathrm{~S}$ ]-labeled PCR products were run undigested or after single or double digestion with Avall and Spel. C, Summary of the expected sizes of the restriction fragments from single and double digests of the 446 bp topo $\| \alpha$ and topo II $\beta$ PCR products with Avall and Spel.

mine which of the bands was derived from topo Il $\alpha$ and which from topo $\| \beta$ mRNA, the mixture of PCR products was digested with Avall and Spel, individually and in combination, prior to electrophoresis (Fig. 2B). Comparison of the sizes of the restriction fragments obtained with those predicted from the cDNA sequence revealed that the upper band of the undigested DNA corresponded to topo II $\alpha$ and the lower band to topo $\| \beta$ (Fig. 2, B and C). The different electrophoretic mobilities of the topo $\| \alpha / \beta 446 \mathrm{bp}$ PCR products was unexpected, but not unprecedented. Other DNAs, of exactly the same size but different sequence, have been observed to exhibit mobilities differing by up to $10 \%$ under nondenaturing electrophoretic conditions. This phenomenon is believed to result from differences in kinks that form at specific sequences in double-stranded DNA (Sambrook et al, 1989).

\section{PCR-Based Relative Quantitation of Topo Il $\alpha$ and Topo II $\beta$ in NSCLC Cell Lines}

To determine the optimal conditions required to quantitate topo $\| \alpha$ and topo $\| \beta$ mRNA levels, poly $(\mathrm{A}+) \mathrm{RNA}$ extracted from 13 NSCLC cell lines was used as a template for RT-PCR using the single pair of gene- specific primers. Topo II cDNA levels were quantitated relative to the cDNA for the ubiquitously and uniformly expressed transferrin receptor (TFRR) to assist in normalizing for the variability in cDNA synthesis among cell lines and tissue samples, as well as for variability in mRNA extraction and quantitation (Campling et al, 1997b).

The 13 NSCLC cell lines were found to express a wide range of relative levels of topo II $\alpha$ and $\beta$ mRNAs. For topo Il $\alpha$, there was a 12-fold range: from 0.106 for the SK-LC6 large cell lung cancer cell line to 1.298 for the A549 adenocarcinoma cell line (Fig. 3A). For topo $\| \beta$, the range was somewhat narrower (5.5-fold): from 0.171 for the FR-E large cell lung cancer cell line to

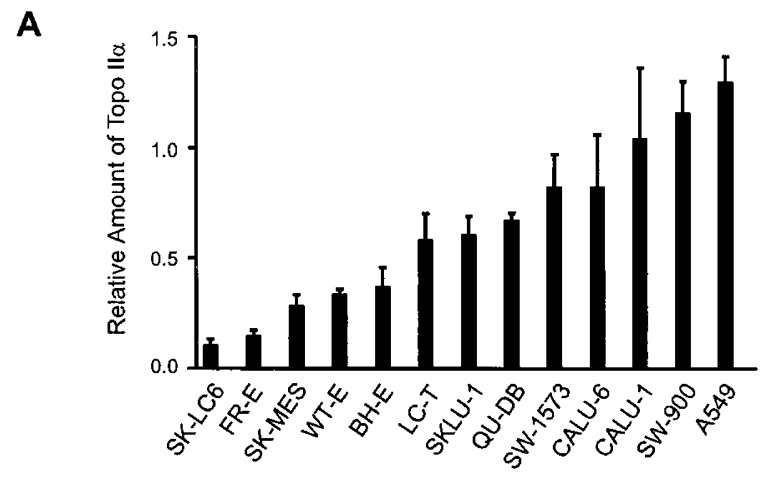

B

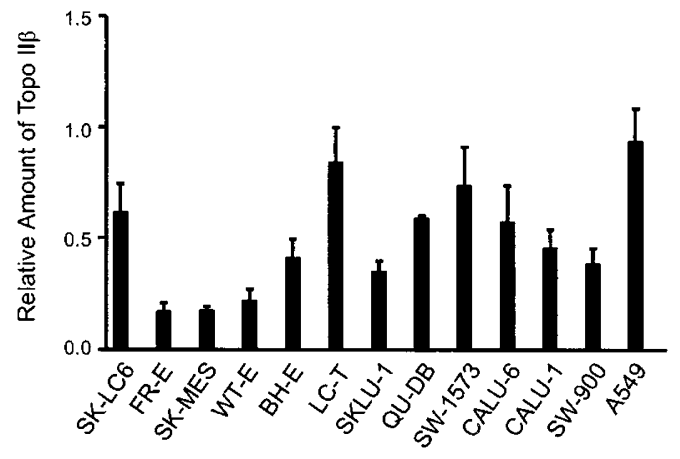

C

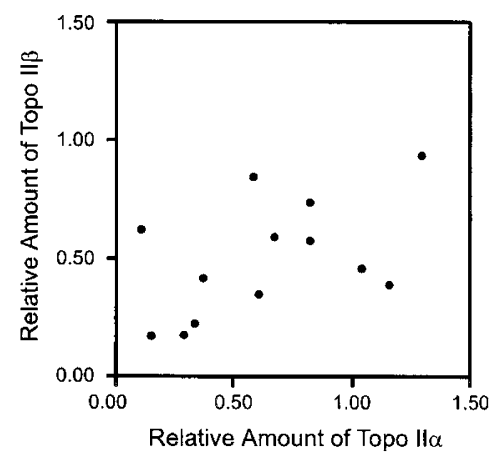

Figure 3.

Relative levels of topo II mRNAs in NSCLC cell lines. The relative levels of $A$, topo $\| \alpha$ mRNA, and $B$, topo $\| \beta$ mRNA in 13 NSCLC cell lines were determined by RT-PCR using poly $(A+)$ RNA and a single pair of gene-specific primers. All values were normalized to TFRR mRNA levels as described in the "Materials and Methods" section. The bars represent the mean ( \pm SEM) of three independent PCR amplifications of the same cDNA. $C$, Correlation between the relative amounts of topo $\| \alpha$ and topo $\| \beta$ mRNAs in the NSCLC cell lines. The Pearson correlation coefficient was $0.51(p=0.074)$. 
0.936 for the A549 cell line (Fig. 3B). Analysis of the relative topo $\|_{\alpha}$ and topo $\| \beta$ mRNA levels in the NSCLC cell lines showed a correlation coefficient of 0.51 , which was not statistically significant $(p=0.074)$ (Fig. 3C). The relative expression levels of the two isoforms were similar in most cell lines, although there were several notable exceptions. For example, topo Il $\alpha$ mRNA levels were approximately three times higher than the topo $\| \beta$ mRNA levels in the SW900 squamous cell lung cancer cell line. In contrast, the large cell lung cancer cell line, SK-LC6, expressed approximately six times as much topo $\| \beta$ mRNA as topo $\| \alpha$ mRNA. Thus, even in rapidly dividing tumor cell lines, the relative proportion of the two isoforms varies markedly.

\section{Application of RT-PCR for Measuring Topo II $\alpha$ and $\beta$ mRNAs in Clinical Samples}

RNA from tumor banks is typically available as total RNA, rather than poly $\left(\mathrm{A}^{+}\right) \mathrm{RNA}$. Consequently, we determined whether reliable results could be obtained with our RT-PCR method by using total RNA as the starting material. Further, to investigate the error involved in the reverse transcription of patient sample total RNA to cDNA, three different cDNA preparations were made on three different days from each of two total RNA samples: a tumor sample from a patient with NSCLC and a sample of normal lung tissue from a different patient. Preliminary experiments indicated that by using 29 cycles, quantitatively amplified products for both the topo $\| \alpha / \beta$ and TFRR reactions were obtained (Fig. 4). The relative amounts of topo $11 \alpha$ mRNA were $2.79 \pm 0.10$ for the tumor sample (33T) and $0.74 \pm 0.19$ for the normal lung sample $(54 \mathrm{~N})$. For topo $\| \beta$ mRNA, the relative values were $2.27 \pm 0.60$ and $0.37 \pm 0.07$ for $33 \mathrm{~T}$ and $54 \mathrm{~N}$, respectively. The variation for the reverse transcription of total RNA to

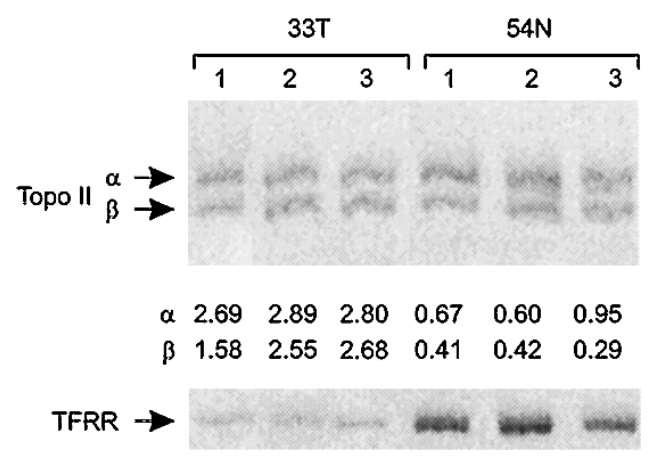

\section{Figure 4.}

Polyacrylamide gel of topo $\| \alpha$ and topo II $\beta$ RT-PCR products obtained using total RNA from clinical samples. cDNA was synthesized using total RNA isolated from a lung tumor sample (33T) and a normal lung tissue (54N) on three different days (denoted 1,2, and 3) and subjected to RT-PCR using a single pair of topo II gene-specific primers on the same day. The bands corresponding to topo $\| \alpha$, topo $\| \beta$, and TFRR mRNAs are indicated and the relative amounts of the topo II $\alpha$ and $\beta$ mRNAs (normalized to TFRR mRNA) for the individual cDNA preparations are shown between the gels. The mean $( \pm \mathrm{sD})$ topo $\| \alpha$ and topo $\| \beta$ mRNA levels in the lung tumor tissue 33T were $2.79 \pm 0.10$ and $2.27 \pm 0.60$, respectively. For the normal lung tissue $54 \mathrm{~N}$, the values were $0.74 \pm 0.19$ and $0.37 \pm 0.07$, respectively.
cDNA (19\%) in three separate experiments could be almost entirely explained by the variation introduced by replicate RT-PCR alone (17\%). This suggests that there is little variation from one time to the next in cDNA synthesis for the same patient sample and that PCR results from one cDNA synthesis should be sufficient and reliable for patient sample analyses.

\section{Topo II $\alpha$ and $\beta$ mRNAs in Paired NSCLC Tumor and Normal Lung Tissue Samples}

Levels of topo II $\alpha$ and $\beta$ mRNAs were evaluable in 25 of the 26 paired samples from patients with NSCLC. Topo Il $\alpha$ mRNA levels were significantly different in paired tumor and normal lung $(p<0.001)$, with approximately 7-fold higher levels in the tumor. In contrast, there was no significant difference in mean topo $\| \beta$ mRNA levels in tumor and normal lung ( $p=$ 0.380 ). Thus, the mean levels of topo $\| \alpha$ mRNA in normal lung tissue were approximately 7 -fold lower than levels of topo $\| \beta$ mRNA, whereas similar levels of the two mRNAs were expressed in tumor tissue, largely because of an increase in topo Il $\alpha$ (Fig. 5, A and B). Despite the marked difference in topo $\| \alpha$ mRNA levels in tumor and normal lung, there was no significant difference in total topo II expression $(\alpha+\beta)$ between tumor and normal lung samples ( $p=0.111)$. The correlation between the topo $\| \alpha$ and topo $\| \beta$ mRNA levels in the tumor samples was significant (correlation coefficient $0.552, p=0.004$ ). However, the correlation between topo II $\alpha$ and topo II $\beta$ mRNA levels in normal lung was not (correlation coefficient 0.348, $p=0.089$ ).

Further analyses of the data from the squamous cell and adenocarcinoma samples suggest that there may be differences in topo II mRNA levels between these histologic subtypes. The topo $\| \alpha$ mRNA levels were significantly increased in each of these histologic tumor subtypes compared with paired normal lung tissue $(p<0.02)$ (Fig. 5, C and D). However, the total topo II ( $\alpha$ plus $\beta$ ) mRNA levels were significantly different in the squamous cell carcinomas $(n=10)$ compared with the adenocarcinoma samples $(n=12)$ ( $p=0.006)$. Thus, the mean topo Il $\alpha$ mRNA levels in the squamous cell tumors were approximately onehalf of those in the adenocarcinoma samples, although this difference did not reach statistical significance ( $p=0.110$ ) (Fig. $5 \mathrm{C}$ ). The mean topo II $\beta$ mRNA levels in the squamous cell tumors were approximately one-half those of the adenocarcinoma ( $p=$ $0.003)$, or the paired normal lung samples ( $p=0.007$ ) (Fig. 5, E and F). In contrast, topo II $\beta$ levels did not differ between the adenocarcinoma and paired normal lung samples.

\section{Discussion}

Differences in the sensitivity of the human topo II $\alpha$ and $\beta$ isoforms to various chemotherapeutic agents have been observed in vitro (Drake et al, 1989) and in temperature-sensitive yeast mutants heterologously expressing the human topo II cDNAs (Meczes et al, 
A

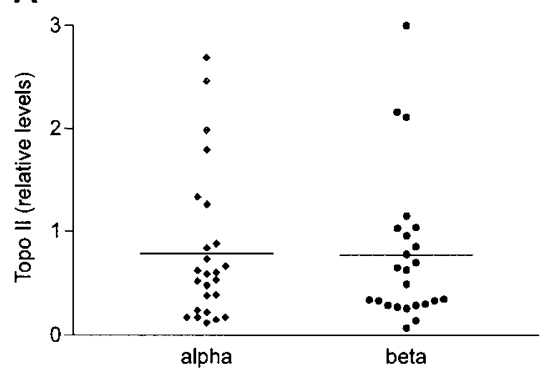

C

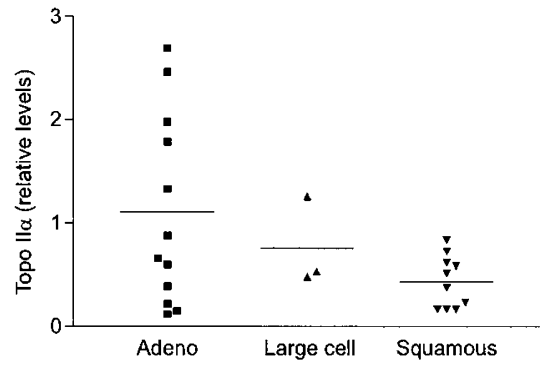

E

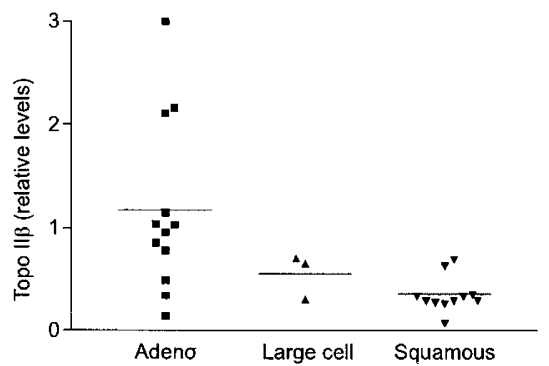

B

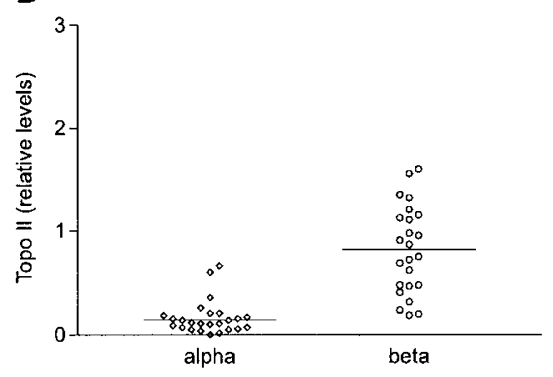

D

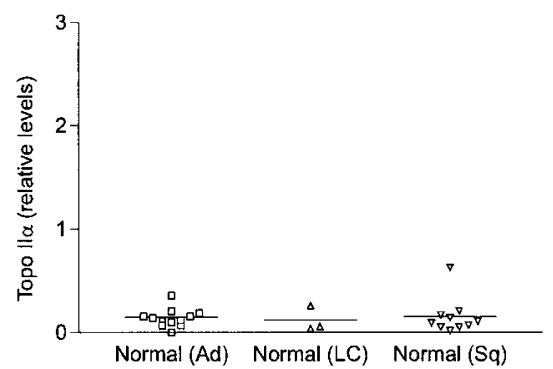

F

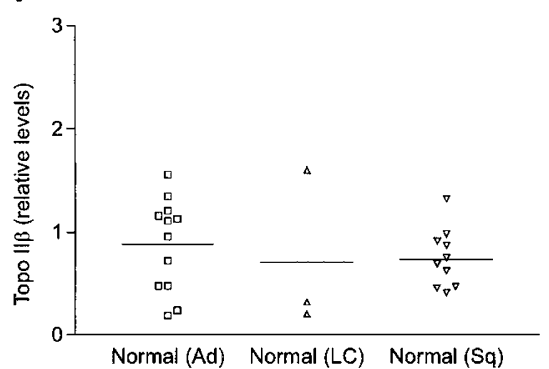

\section{Figure 5.}

Topo $\| \alpha$ and topo II $\beta$ mRNA levels in NSCLC tumor samples and paired normal lung tissue. Topo II $\alpha$ and $\beta$ mRNAs were quantitated by RT-PCR relative to TFRR mRNA. Bars indicate mean topo II expression levels in each column. The levels of topo II $\alpha$ mRNA were compared with topo II $\beta$ mRNA in NSCLC samples $(A)$, and normal lung $(B)$. Levels of topo II $\alpha(C, D)$ and $\beta(E, F)$ mRNAs are shown for different histologic types of NSCLC $(C, E)$, and paired normal lung tissue $(D, F)$. Abbreviations: Ad, adenocarcinoma; LC, large cell carcinoma; Sq, squamous cell carcinoma.

1997). These observations have prompted the suggestion that chemotherapy could be designed to target either topo II $\alpha$ or $\beta$ specifically, providing a means to overcome drug resistance caused by changes in a single isoform. However, the relationships between drug sensitivity and expression levels of the individual topo II isoforms in a clinical context remain unclear. Measurement of topo $\| \beta$ protein or mRNA levels, in addition to topo Il $\alpha$ levels, has recently become more common in lung cancer investigations. In studies to date, antibodies, cDNA probes, or PCR primers specific for each topo II isoform have been used, so that direct comparison of topo $\mathrm{II} \alpha$ and topo II $\beta$ levels has not been possible (Dingemans et al, 1999; Galimberti et al, 1998; Giaccone et al, 1995; Holden et al, 1992; Houlbrook et al, 1996; Syahruddin et al, 1998; Turley et al, 1997). Because both isoforms likely contribute to drug sensitivity, it would be advantageous to be able to measure the proportion of topo II mRNA represented by each isoform in a given sample. One technique that would permit such a comparison would be immunoblotting using antisera specific for a peptide sequence that is present in both isoforms (Webb et al, 1993). However, the direct quantitation of protein levels by immunoblotting is labor intensive and fraught with technical difficulties, particularly with respect to the large-scale analysis of clinical samples. In contrast, the PCR-based method described here, using a single pair of gene-specific primers for equivalent amplification of the topo II $\alpha$ and $\beta$ mRNAs followed by nondenaturing electrophoresis, provides an efficient and convenient method for the simultaneous relative quantification of the two isoforms, which is readily applicable to studies involving large numbers of clinical samples. The variability of repeated estimates between experiments using the same source of cDNA was reasonable $(17 \%$ of the mean) (Fig. 3), and repeated cDNA synthesis from total RNA samples from tumor or normal lung tissue did not markedly increase this variation (Fig. 4). The technique was able to detect a wide range in relative mRNA levels in clinical samples for both topo $\| \alpha$ (0.01 to 2.9) and topo 
$\| \beta$ (0.21 to 3.01). The range of topo Il $\alpha$ mRNA levels was 12-fold in the NSCLC cell lines, 22-fold in the tumor samples, and 68-fold in normal lung tissue, whereas the range of values for topo $\| \beta$ was 5.5 -fold, 38-fold, and 13-fold, respectively. The method is sensitive, because both mRNAs could be quantitated in $96 \%$ of the clinical samples examined, including normal lung tissues, in which some methods are unable to detect topo $\|_{\alpha}$ (Giaccone et al, 1995). These results compare favorably with the RT-PCR-based study of Galimberti et al (1998), in which topo II $\alpha$ and topo II $\beta$ mRNAs were detected in $82 \%$ and $94 \%$, respectively, of 51 NSCLC samples examined.

Topo Il $\alpha$ mRNA levels were very low in normal lung tissue and were significantly higher in the NSCLC samples (Fig. 5, A and B). Furthermore, mean topo Il $\alpha$ mRNA levels in normal lung tissues were approximately 7 -fold lower than topo II $\beta$ levels (Fig. 5B). In contrast, the tumor samples expressed similar levels of the two isoforms because of a marked increase in the topo Il $\alpha$ mRNA levels (Fig. 5A). Topo $\| \beta$ mRNA levels in the tumor samples and normal lung tissues were comparable. Thus, our findings are consistent with the high expression levels of topo Il $\alpha$ generally observed in dividing cells (Wang, 1996) and with other studies that report increased topo II $\alpha$ and similar topo II $\beta$ levels in lung tumors compared to normal lung (Giaccone et al, 1995; Hasegawa et al, 1993; Kreisholt et al, 1998; Syahruddin et al, 1998; Turley et al, 1997).

Our data also indicated that there was no significant correlation between the levels of topo II $\alpha$ and $\beta$ mRNAs in either the NSCLC cell lines or the normal lung and only a moderate correlation in the tumor samples. In the actively dividing NSCLC cell lines, the relative proportion of the two topo II isoforms varied markedly (Fig. 3). Similarly, inspection of the data of Houlbrook et al (1996) suggests that there is no correlation between the rank order of topo II $\alpha$ levels and the rank order of topo $\| \beta$ levels in their panel of SCLC and NSCLC cell lines. Two of four previous lung cancer studies in which the levels of both topo II $\alpha$ and $\beta$ mRNAs and/or proteins were quantitated reported no correlation between topo II $\alpha$ and $\beta$ mRNA levels (Galimberti et al, 1998; Giaccone et al, 1995). However, consistent with our findings, a moderate correlation between topo $\| \alpha$ and $\beta$ mRNA levels was observed in the other two studies (Dingemans et al, 1999; Syahruddin et al, 1998). Such a correlation would not necessarily be expected because the promoter regions of the TOP $2 A$ and TOP2B genes are structurally very different (Hochhauser et al, 1992; $\mathrm{Ng}$ et al, 1997) and a lack of coordinate expression would be consistent with the known differences in the regulation of these two genes. The basis for the discrepant findings among these independent studies is unknown. Unfortunately, unlike the present investigation, the four previous studies used analytical methods that did not allow the relative levels of topo II $\alpha$ and $\beta$ to be compared directly.

The relative proportions of topo II $\alpha$ and $\beta$ mRNAs in squamous cell tumors and adenocarcinomas were observed to be generally similar, but the levels of the two isoform mRNAs were significantly less in the squamous cell tumors than in the adenocarcinomas (Fig. 5, C and E). This expression pattern reflects a smaller increase in topo Il $\alpha$ levels in the squamous cell tumors than in the adenocarcinomas when compared with the normal lung tissues (Fig. 5, C and D), and a decrease in topo II $\beta$ levels in the squamous, but not in the adenocarcinoma, samples relative to normal lung (Fig. 5, E and F). In other clinical studies of topo II $\alpha$ and $\beta$ expression in lung cancer, the different histologic subtypes have not been analyzed (Giaccone et al, 1995; Syahruddin et al, 1998). Thus, our study is the first to report a histologic typerelated difference in topo II mRNA levels. However, the number of samples of each type was small $(n=10-12)$, and consequently, additional larger studies are needed to determine whether such a relationship truly exists, and whether it correlates with drug resistance, expression levels of any other tumor markers, and/or clinical outcome.

The clinical relevance of topo II $\alpha$ and $\beta$ mRNA or protein levels in lung cancer patients is only beginning to be assessed. It has recently been reported that 7 of 10 SCLC samples obtained after treatment of patients with the topo II poison VP-16 expressed lower levels of topo Il $\alpha$ protein compared with tumor samples obtained before chemotherapy (Kreisholt et al, 1998). Thus, it was suggested that topo Il $\alpha$ levels may be a key determinant in the response of SCLC tumors to chemotherapy with topo II targeting drugs. Unfortunately, topo II $\beta$ levels were not evaluated. In another study of SCLC patients, eight post-chemotherapy tumor samples showed no change in topo II $\alpha$ levels, but topo II $\beta$ levels were increased (Dingemans et al, 1999). In this same study, analysis of biopsy samples from 93 untreated patients indicated that high topo Il $\alpha$ levels were prognostic for shorter survival. In addition, high topo II $\beta$ mRNA levels were found to be predictive of lower overall and complete response rates, whereas low-level expression of both topo II $\alpha$ and $\beta$ were of prognostic value for complete response. Similar results suggesting the relevance of topo II levels to different indicators of clinical outcome have been reported in other tumor types, including breast cancer (Kreipe et al, 1993; Rudolph et al, 1999; Sandri et al, 1996) and esophageal cancer (Ohashi et al, 1999).

In summary, we have shown that the simultaneous measurement of topo II $\alpha$ and $\beta$ mRNA levels by RT-PCR can be achieved using a single pair of genespecific primers. Our method is reliable and convenient, and it can be used to quantitate the relative levels of the two mRNAs in both normal and tumor tissue samples using either total RNA or poly $(A+)$ RNA. We found that topo $\| \alpha$ mRNA levels were increased in NSCLC tissues compared with normal lung, but topo II $\beta$ mRNA levels were not, and furthermore, that the two isoforms were expressed at similar levels in these tumors. We also observed that both topo II $\alpha$ and $\beta$ mRNA levels were lower in squamous cell tumors than in adenocarcinomas. Further analyses of larger numbers of clinical samples are in progress so that the relative expression levels of the topo II isoforms and their relationships to histologic 
subtype, response to chemotherapy, and clinical outcome can be evaluated.

\section{Materials and Methods}

\section{Cell Lines and Patient Samples}

The human SCLC cell line, H209, was used in the initial development of the PCR method for simultaneous detection of topo $\| \alpha$ and $\beta$ mRNAs. The origin of this cell line and its expression levels of topo II $\alpha$ and topo $\| \beta$ proteins and mRNAs have been described previously (Mirski et al, 1993). Thirteen NSCLC cell lines (four adenocarcinoma, four large cell carcinoma, four squamous cell carcinoma, and one bronchoalveolar carcinoma) were used for further validation of the RT-PCR method and have also been described previously (Campling et al, 1992; Young et al, 1999). Total RNA from normal and malignant tissue from 26 patients with NSCLC was obtained from the Canadian Lung Tumor Bank, established in association with the National Cancer Institute of Canada, Clinical Trials Group. Of the 26 tumor samples, 12 were adenocarcinomas, 11 were squamous cell carcinomas, and 3 were large cell carcinomas.

\section{mRNA Isolation and cDNA Synthesis}

Poly $\left(A^{+}\right)$RNA was extracted from 5 to $10 \times 10^{6}$ exponentially growing cells using the Micro-Fast Track mRNA Isolation Kit (Invitrogen, San Diego, California) or the QuickPrep Micro mRNA Purification Kit (Pharmacia Biotech Inc., Baie d'Urfé, Quebec, Canada). cDNA was synthesized as follows: $0.3 \mu \mathrm{g}$ of poly $\left(\mathrm{A}^{+}\right)$ RNA was mixed with $100 \mathrm{ng}$ of random hexanucleotide primers (Pharmacia Biotech Inc.) and diethylpyrocarbonate-treated water in a volume of 12 $\mu$ l. Samples were heated at $70^{\circ} \mathrm{C}$ for 10 minutes and then immediately chilled on ice for 10 minutes. Each sample was adjusted to a reaction volume of $20 \mu \mathrm{l}$ containing $2 \mathrm{~mm}$ dNTPs (Pharmacia Biotech Inc.), 10 $\mathrm{mm}$ dithiothreitol, $1.0 \mathrm{U} / \mu \mathrm{l}$ RNAguard (Pharmacia Biotech Inc.), and $1 \mathrm{X}$ avian myeloblastosis virus reverse transcriptase buffer (Life Sciences Inc., St. Petersburg, Florida). The reactions were heated at $42^{\circ} \mathrm{C}$ for 2 minutes, and then avian myeloblastosis virus reverse transcriptase (Life Sciences Inc.) was added to a final concentration of $0.4 \mathrm{U} / \mu \mathrm{l}$. The tubes were incubated at $42^{\circ} \mathrm{C}$ for 40 minutes, followed by $95^{\circ} \mathrm{C}$ for 10 minutes and $24^{\circ} \mathrm{C}$ for 10 minutes. cDNA was synthesized from $1 \mu \mathrm{g}$ of total RNA from the patient samples in a similar manner. The cDNAs from the lung cancer cell lines and the patient samples were diluted 10-fold and 3 -fold, respectively, and stored at $-20^{\circ} \mathrm{C}$ until required.

\section{PCR Amplification of Topo Il $\alpha$ and Topo II $\beta$ cDNA and Restriction Enzyme Analysis}

To amplify topo $\| \alpha / \beta$ cDNAs simultaneously, the sense forward primer 5'-CAGATCATGGAAAATGC TGA-3' (nucleotides 1498-1517 of TOP2A and 15461565 of $T O P 2 B$ ) and the antisense reverse primer
5'-GCAGCATCATCTTCAGGACC-3' (nucleotides 1924-1943 of TOP2A and 1972-1991 of TOP2B) were used with the Expand Long Template PCR System (Boehringer Mannheim Corporation, Laval, Québec, Canada). [ $\left.{ }^{35} \mathrm{~S}\right] \mathrm{dATP}(1250 \mathrm{Ci} / \mathrm{mmol})$ (Dupont NEN, Boston, Massachusetts) $(17.5 \mu \mathrm{Ci})$ was added to a 10 $\mu$ l PCR mixture containing $2 \mu \mathrm{l}$ of cDNA. Second strand cDNA synthesis was achieved by 1 minute denaturation at $94^{\circ} \mathrm{C}, 1$ minute annealing at $58^{\circ} \mathrm{C}$, and 3 minutes elongation at $68^{\circ} \mathrm{C}$ in a PCT-100 thermocycler (MJ Research Inc., Incline Village, Nevada). Amplification of the double-stranded cDNA was carried out for 25 cycles, each consisting of $35 \mathrm{sec}-$ onds denaturation at $94^{\circ} \mathrm{C}, 1$ minute annealing at $58^{\circ} \mathrm{C}$, and 1 minute elongation $68^{\circ} \mathrm{C}$. The final cycle was a 6.5 minutes elongation at $68^{\circ} \mathrm{C}$ followed by slow cooling to room temperature. After a 5-fold dilution, $5 \mu \mathrm{l}$ of the reaction mixture was run on a $2 \%$ agarose gel, and the DNA was visualized by staining with ethidium bromide.

To discriminate between the topo II $\alpha$ and topo II $\beta$ PCR products, the reaction mixture obtained with H209 cDNA was subjected to single and double restriction digestions with Avall and Spel in the appropriate buffer at $37^{\circ} \mathrm{C}$ for 2 hours (New England Biolabs Inc., Mississauga, Ontario, Canada). Polyacrylamide gel electrophoresis was then carried out as follows: $4.5 \mu$ of $\left[{ }^{35} \mathrm{~S}\right] \mathrm{dATP}$-labeled PCR product from a $10 \mu \mathrm{l}$ reaction was mixed with $1 \mu \mathrm{l}$ of $5 \times$ bromophenol blue loading dye solution (20\% Ficoll 400, 0.1 M EDTA, 1\% SDS, 0.25\% bromophenol blue) and run on $8 \times 16 \mathrm{~cm}, 0.75 \mathrm{~mm}, 5 \%$ polyacrylamide gel in Tris-Borate-EDTA buffer (0.089 M Tris base, $0.089 \mathrm{M}$ boric acid, $0.02 \mathrm{M}$ EDTA, $\mathrm{pH}$ 8.0) at constant voltage $(150 \mathrm{~V})$ for approximately 2.5 hours. The gel was then dried, and the $\left[{ }^{35} \mathrm{~S}\right] \mathrm{dATP}$ incorporated into the PCR products was quantified by exposure of the dried gel to a Storage Phosphor Screen GP (Kodak, Rochester, New York) for 23 to 25 hours and then by analysis using a STORM 820 Phosphorlmager (Molecular Dynamics, Sunnyvale, California) and ImageQuaNT Software, version 4.2a (Molecular Dynamics).

\section{PCR-Based Relative Quantitation of Topo Il $\alpha$ and Topo II $\beta$ mRNA Levels in NSCLC Cell Lines and Patient Samples}

To correct for the quantity of cDNA in each PCR reaction, levels of transferrin receptor (TFRR) mRNA in the NSCLC cell lines or patient samples were determined by RT-PCR. A 512-bp product was generated using the sense forward primer 5'-GGATAAAGCGGT TCTTGGTACCAGC-3' (nucleotides 1547-1571 of TFRR) and antisense reverse primer 5'-TGGAA GTAGCACGGAAGAAGTCTCC-3' (nucleotides 20342058 of $T F R R$ ). The annealing temperature for the TFRR primers was $58^{\circ} \mathrm{C}$.

Amplification of the topo $\| \alpha / \beta$ cDNAs and the TFRR cDNA was carried out in separate reactions using the same conditions except for the number of PCR cycles. Preliminary reactions were carried out in which $2 \mu$ l of cDNA from each of the 13 NSCLC cell lines was 
amplified for 24 cycles using the topo $\| \alpha / \beta$ and TFRR primers in the absence of $\left[{ }^{35} \mathrm{~S}\right] \mathrm{dATP}$. Cell lines were identified that expressed the highest and lowest levels of topo $\| \alpha / \beta$ or TFRR mRNAs (based on ethidium bromide visualization of DNA in an agarose gel). These cDNAs were then amplified in the presence of $\left[{ }^{35} \mathrm{~S}\right] \mathrm{dATP}$ for different numbers of cycles and amounts of cDNA template to determine the optimal number of PCR cycles such that (a) the cDNA from the highly expressing cell lines would be within the exponential range of amplification, (b) the cDNA from the low-level expressing cell lines would still be readily detected, and (c) the amount of product obtained was directly proportional to the amount of cDNA template used. Similar experiments were also performed on the clinical samples to confirm that RT-PCR reactions were in the exponential range. Based on these experiments, 25 and 24 cycles were used in subsequent analyses of topo II $\alpha / \beta$ and TFRR levels, respectively.

\section{RT-PCR Quantitation and Statistics}

Net radioactivity data (band density of PCR product minus the density of local gel background) from each experiment were normalized in two ways. First, the band density for each PCR product was divided by the mean band density for all the products on the same gel to control for differences from one gel to the next and to compensate for radioactive decay between experiments. Second, to account for variability in mRNA extraction, mRNA quantitation, and cDNA synthesis, the topo $\| \alpha$ and topo $\| \beta$ values from the first calculation were divided by the TFRR values. To investigate the extent of variability in the PCR-based quantitation, RT-PCR amplification with the topo $\| \alpha / \beta$ and TFRR primers was carried out three times on three different days using a single cDNA preparation for each of the 13 cell lines. Descriptive statistics were calculated for the relative levels of topo II $\alpha$ and topo II $\beta$ mRNA using the Corel Quattro Pro Spreadsheet Software (Corel Inc., Ottawa, Ontario, Canada) and reported as the mean ( \pm SEM) of results obtained in three independent experiments. The variability between experiments was acceptable, with an average SEM of $17.2 \%$ (range $4.8 \%-30.5 \%$ ) for topo II $\alpha$ and $17.6 \%$ (range $1.5 \%-28.1 \%$ ) for topo $I I \beta$.

Statistical analyses on data from tumor and normal lung samples were performed using the Systat software package, version 7.0 (SPSS Inc., Chicago, Illinois). The distribution of mRNA levels was skewed, and consequently, the data were transformed (naturallogarithmic) to more closely approximate a normal distribution prior to statistical analysis. Statistical significance was evaluated using a paired $t$ test, and differences were regarded as significant when $p$ was $<0.05$.

\section{Acknowledgements}

The authors wish to thank Dr. Ming-Sound Tsao of the Mt. Sinai Hospital in Toronto for providing the RNA samples from the patients with NSCLC. We also thank
Ms. Iva Kosatka, Ms. Kathy Sparks, and Ms. Libby Eastman for technical assistance, and Ms. Maureen Rogers for assistance in preparing the manuscript.

\section{References}

Campling BG, Baer KA, Gerlach JH, Lam YM, Cole SP, and Mirski SEL (1997a). Topoisomerase II levels and drug response in small cell lung cancer. Int J Oncol 10:885-893.

Campling BG, Haworth AC, Baker HM, Greer DL, Holden JJ, Bradley EC, Pym J, and Dexter DF (1992). Establishment and characterization of a panel of human lung cancer cell lines. Cancer 69:2064-2074.

Campling BG, Young LC, Baer KA, Lam YM, Deeley RG, Cole SPC, and Gerlach JH (1997b). Expression of the MRP and MDR1 multidrug resistance genes in small cell lung cancer. Clin Cancer Res 3:115-122.

Cornarotti M, Tinelli S, Willmore E, Zunino F, Fisher LM, Austin CA, and Capranico G (1996). Drug sensitivity and sequence specificity of human recombinant DNA topoisomerase $\| \alpha$ (p170) and $\| \beta$ (p180). Mol Pharmacol 50:14631471.

Davies SL, Bergh J, Harris AL, and Hickson ID (1997). Response to ICRF-159 in cell lines resistant to cleavable complex-forming topoisomerase II inhibitors. $\mathrm{Br} \mathrm{J}$ Cancer 75:816-821.

Dingemans AM, Witlox MA, Stallaert RA, van der Valk $P$, Postmus PE, and Giaccone G (1999). Expression of DNA topoisomerase $\| \alpha$ and topoisomerase $\| \beta$ genes predicts survival and response to chemotherapy in patients with small cell lung cancer. Clin Cancer Res 5:2048-2058.

Dingemans AM, Pinedo HM, and Giaccone G (1998). Clinical resistance to topoisomerase-targeted drugs. Biochim Biophys Acta 1400:275-288.

Drake FH, Hofmann GA, Bartus HF, Mattern MR, Crooke ST, and Mirabelli CK (1989). Biochemical and pharmacological properties of p170 and p180 forms of topoisomerase II. Biochemistry 28:8154-8160.

Fattman CL, Allan WP, Hasinoff BB, and Yalowich JC (1996). Collateral sensitivity to the bisdioxopiperazine dexrazoxane (ICRF-187) in etoposide (VP-16)-resistant human leukemia K562 cells. Biochem Pharmacol 52:635-642.

Galimberti S, Marchetti A, Buttitta F, Carnicelli V, Pellegrini S, Bevilacqua G, and Petrini M (1998). Multidrug resistance related genes and p53 expression in human non small cell lung cancer. Anticancer Res 18:2973-2976.

Giaccone G, Gazdar AF, Beck H, Zunino F, and Capranico G (1992). Multidrug sensitivity phenotype of human lung cancer cells associated with topoisomerase II expression. Cancer Res 52:1666-1674.

Giaccone G, van Ark-Otte J, Scagliotti GV, Capranico G, van der Valk P, Rubio GJ, Dalesio O, Lopez R, Zunino F, Walboomers J, and Pinedo HM (1995). Differential expression of DNA topoisomerases in non-small cell lung cancer and normal lung. Biochim Biophys Acta 1264:337-346.

Guinee DG, Holden JA, Benfield JR, Woodward ML, Przygodzki RM, Fishback NF, Koss MN, and Travis WD (1996). Comparison of DNA topoisomerase Il $\alpha$ expression in small cell and nonsmall carcinoma of the lung. In search of a mechanism of chemotherapeutic response. Cancer 78:729735. 
Hasegawa T, Isobe K-I, Nakashima I, and Shimokata K (1993). Higher expression of topoisomerase II in lung cancers than normal lung tissues: Different expression pattern from topoisomerase I. Biochem Biophys Res Commun 195:409414.

Hochhauser D, Stanway CA, Harris AL, and Hickson ID (1992). Cloning and characterization of the 5 '-flanking region of the human topoisomerase Il $\alpha$ gene. J Biol Chem 267: 18961-18965.

Holden JA, Rolfson DH, and Wittwer CT (1992). The distribution of immunoreactive topoisomerase II protein in human tissues and neoplasms. Oncol Res 4:157-166.

Houlbrook S, Harris AL, Carmichael J, and Stratford IJ (1996). Relationship between topoisomerase II levels and resistance to topoisomerase II inhibitors in lung cancer cell lines. Anticancer Res 16:1603-1610.

Kasahara K, Fujiwara Y, Sugimoto Y, Nishio K, Tamura T, Matsuda T, and Saijo N (1992). Determinants of response to the DNA topoisomerase II inhibitors doxorubicin and etoposide in human lung cancer cell lines. J Natl Cancer Inst 84:113-118.

Kreipe $H$, Alm P, Olsson $H$, Hauberg $M$, Fischer L, and Parwaresch R (1993). Prognostic significance of a formalinresistant nuclear proliferation antigen in mammary carcinomas as determined by the monoclonal antibody Ki-S1. Am J Pathol 142:651-657.

Kreisholt J, Sorensen M, Jensen PB, Nielsen BS, Andersen CB, and Sehested M (1998). Immunohistochemical detection of DNA topoisomerase $\| \alpha$, P-glycoprotein and multidrug resistance protein (MRP) in small-cell and non-small-cell lung cancer. Br J Cancer 77:1469-1473.

Lang AJ, Mirski SE, Cummings HJ, Yu Q, Gerlach JH, and Cole SPC (1998). Structural organization of the human TOP2A and TOP2B genes. Gene 221:255-266.

Larsen AK and Skladanowski A (1998). Cellular resistance to topoisomerase-targeted drugs: From drug uptake to cell death. Biochim Biophys Acta 1400:257-274.

Meczes EL, Marsh KL, Fisher LM, Rogers MP, and Austin CA (1997). Complementation of temperature-sensitive topoisomerase II mutations in Saccharomyces cerevisiae by a human TOP2 $\beta$ construct allows the study of topoisomerase II $\beta$ inhibitors in yeast. Cancer Chemother Pharmacol 39:367375 .

Mirski SEL and Cole SPC (1997). Multidrug resistance in small cell lung cancer. In: Bernal SD, editor. Drug Resistance in Oncology. New York: Marcel Dekker, 27-75.

Mirski SEL, Evans CD, Almquist KC, Slovak ML, and Cole SPC (1993). Altered topoisomerase Il $\alpha$ in a drug-resistant small cell lung cancer cell line selected in VP-16. Cancer Res 53:4866-4873.

Ng SW, Liu Y, and Schnipper LE (1997). Cloning and characterization of the 5 '-flanking sequence for the human DNA topoisomerase II $\beta$ gene. Gene 203:113-119.

Nitiss JL and Beck WT (1996). Antitopoisomerase drug action and resistance. Eur J Cancer 32A:958-966.
Ohashi Y, Sasano H, Yamaki H, Shizawa S, Kikuchi A, Shineha R, Akaishi T, Satomi S, and Nagura H (1999). Topoisomerase Il $\alpha$ expression in esophageal squamous cell carcinoma. Anticancer Res 19:1873-1880.

Perrin D, van Hille B, and Hill BT (1998). Differential sensitivities of recombinant human topoisomerase $\mathrm{Il} \alpha$ and $\beta$ to various classes of topoisomerase II-interacting agents. Biochem Pharmacol 56:503-507.

Rudolph P, MacGrogan G, Bonichon F, Frahm SO, de Mascarel I, Trojani M, Durand M, Avril A, Coindre JM, and Parwaresch R (1999). Prognostic significance of Ki-67 and topoisomerase Il $\alpha$ expression in infiltrating ductal carcinoma of the breast. A multivariate analysis of 863 cases. Breast Cancer Res Treat 55:61-71.

Sambrook J, Fritsch EF, and Maniatis T (1989). Molecular Cloning: A Laboratory Manual, 2nd ed. Cold Spring Harbor, NY: Cold Spring Harbor Laboratory Press.

Sandri MI, Hochhauser D, Ayton P, Camplejohn RC, Whitehouse R, Turley H, Gatter K, Hickson ID, and Harris AL (1996). Differential expression of the topoisomerase Il $\alpha$ and $\beta$ genes in human breast cancers. Br J Cancer 73:1518-1524.

Sehested M, Wessel I, Jensen LH, Holm B, Oliveri RS, Kenwrick S, Creighton AM, Nitiss JL, and Jensen PB (1998). Chinese hamster ovary cells resistant to the topoisomerase II catalytic inhibitor ICRF-159: A Tyr49Phe mutation confers high-level resistance to bisdioxopiperazines. Cancer Res 58:1460-1468.

Syahruddin E, Oguri T, Takahashi T, Isobe T, Fujiwara $\mathrm{Y}$, and Yamakido M (1998). Differential expression of DNA topoisomerase $\| \alpha$ and $\| \beta$ genes between small cell and non-small cell lung cancer. Jpn J Cancer Res 89:855-861.

Turley H, Comley M, Houlbrook S, Nozaki N, Kikuchi A, Hickson ID, Gatter K, and Harris AL (1997). The distribution and expression of the two isoforms of DNA topoisomerase II in normal and neoplastic human tissues. $\mathrm{Br} \mathrm{J}$ Cancer 75: 1340-1346.

Wang JC (1996). DNA topoisomerases. Annu Rev Biochem 65:635-692.

Webb CF, Eneff KL, and Drake FH (1993). A topoisomerase II-like protein is part of an inducible DNA-binding protein complex that binds $5^{\prime}$ of an immunoglobulin promoter. Nucleic Acids Res 21:4363-4368.

Wessel I, Jensen LH, Jensen PB, Falck J, Rose A, Roerth M, Nitiss JL, and Sehested M (1999). Human small cell lung cancer NYH cells selected for resistance to the bisdioxopiperazine topoisomerase II catalytic inhibitor ICRF-187 demonstrate a functional R162Q mutation in the Walker A consensus ATP binding domain of the $\alpha$ isoform. Cancer Res 59:3442-3450.

Young LC, Campling BG, Voskoglou-Nomikos T, Cole SPC, Deeley RG, and Gerlach JH (1999). Expression of multidrug resistance protein-related genes in lung cancer: Correlation with drug response. Clin Cancer Res 5:673-680. 